\title{
¿De dónde es Julio Cortázar?
}

Miguel Herráez ${ }^{1}$

Estoy apoyado en uno de los pretiles, el izquierdo, del Pont des Arts, recién llegado a París, e inevitablemente me asalta el recuerdo de la Maga y de Oliveira, como siempre ocurre si cruzo el puente desde el Louvre hacia la rive gauche, como siempre que camino sin rumbo fijo por París y que es lo que más me gusta (tras poner el podómetro a cero mientras desayuno en el hotel), lo que se debe hacer en esta ciudad.

La otra noche, en España, mientras paseaba a mi perro, se me acercó otro paseante, también con perro (el suyo era un enorme Collie de pelo largo marrón y de mechas blancas, supe al momento que contaba con más de nueve años), y que resultó ser argentino. Al principio charlamos un rato, cómo no, de cánidos, de razas, de conductas, y de pronto saltamos a hablar de la Argentina. Es un tema que nunca eludo, más bien, si hay ocasión, lo fomento. Él era periodista, me dijo, y había vivido durante un tiempo en Johannesburgo; ahora lo hacía, desde finales de los noventa, en España. Le pregunté de qué parte era y me respondió que de Buenos Aires. Le dije que había estado en varias ocasiones, que me fascinaba, como me fascina todo el espacio del país, desde Jujuy hasta Tierra del Fuego (incluyendo, por supuesto, las Malvinas) y desde Entre Ríos a Mendoza, y que mucho (dos tercios) de ese hechizo se lo debía por haber leído a Julio Cortázar en mi adolescencia. Afirmó con la cabeza, se palpó el mentón de barba poco poblada, y añadió que sí, que Cortázar era un escritor notable, pero (aquí sonrió, ¿su mirada me lanzó un mensaje de disculpa?) que Cortázar no era totalmente argentino. Me sorprendí, aunque, la verdad, cosas semejantes he oído acerca de él en foros de España y de la Argentina, si bien -debo confesarlo- cada vez las escucho menos.

¿QueJulioCortázar no eraun escritor totalmente argentino? No entiendo, le dije. Supuse que no lo diría por el simple hecho de haber nacido en Bélgica y de morir en Francia, tras residir en esta más de treinta años. Me respondió que Cortázar había buscado como tantos argentinos la excusa para salir del país e instalarse en Europa. ¿A la caza del mito parisino?, inquirí. Algo así, respondió. Le remarqué que, en efecto, Cortázar se había ido de una forma voluntaria de la Argentina en 1951, aunque luego, entre 1976 y 1983, su regreso había quedado imposibilitado por su condición de persona non grata para la Junta Militar por entonces en el poder, pero sobre todo destaqué, y eso era lo importante, que Cortázar siempre había escrito en argentino y sobre los argentinos, pese a hacerlo a miles de kilómetros, de ahí que me desorientase su afirmación. De hecho, pensé, no conozco ningún relato, novela o verso de él que se salgan de esa espiral o de sus alrededores.

1 Miguel Herráez (Valencia, 1957) es doctor en Filología Española y catedrático de Literatura Española en Valencia. Ha realizado numerosas estadías universitarias por invitación en la Argentina y París. Ejerció durante un tiempo el periodismo en distintos medios españoles, siendo en la década de los años noventa, corresponsal del diario El Economista, de México DF. Experto en la vida y obra de Julio Cortázar, suya es una de las biografías mejor valoradas desde su publicación, volumen que se reedita constantemente, Julio Cortázar, una biografía revisada. De igual modo, ha publicado libros de cuentos, ensayos y novelas. Sus últimas muestras son Diario de París con 26 notas a pie (ensayo), La vida celular (novela) y Ese día y otros sucesos (cuentos). Títulos suyos han sido traducidos al ruso, portugués, francés e italiano. 
¿Y Borges?, curioseé, ¿es un escritor argentino? Sí, contestó, este sí lo es. Le recordé que Borges vivió en España (Mallorca) en su juventud y que estaba enterrado en Suiza (Ginebra). Sí, añadió, pero es otra actitud. Comprendo, me dije sin comprender, se trata entonces de un problema de actitudes.

En un libro mío, cuando hablo de la captación que ejerció y ejerce París respecto a los escritores latinoamericanos, recojo, además de nombres de otras nacionalidades (he contabilizado por encima de más de un centenar, en un contexto preciso y breve) y de los argentinos íntimos de Cortázar, como los artistas plásticos Julio Silva, Luis Tomasello, o los poetas Saúl Yurkievich o Alejandra Pizarnik y el narrador Osvaldo Soriano, que (sólo) a mediados de los años veinte del siglo XX en París hay nombres argentinos, entre otros, como son los de Leopoldo Marechal, Enrique Larreta, Leopoldo Lugones, Ricardo Güiraldes, Ángel Estrada, Victoria Ocampo, Dionisio Schoo, Oliverio Girondo, y eso sin olvidar otros intelectuales (algunos alejados como Domingo Faustino Sarmiento), como Marcelo T. de Alvear, Lucio V. Mansilla, Otto S. Bemberg, Daniel García Mansilla, Juana González de Devoto, Daniel Cranwell, Saturnino Unzué o Adolfo Bullrich. "Todos los argentinos soñamos con París, desde nuestros años de adolescencia", dejó escrito Manuel Gálvez. No quise preguntarle dónde catalogaría, según sus parámetros referidos al término actitud, por ejemplo a Héctor Bianciotti, escritor bilingüe (español y francés), ni a las dos decenas de narradores del país austral y con obra firme que hoy viven en París. ¿Habría que eliminarlos de la enciclopedia de autores argentinos o incluirlos en una de falsos autores argentinos?

A esas alturas de la conversación mi perro ya se había trepado a la cabezota del Collie, tumbado este de manera paternal y dócil, y las correas de ambos se habían anudado. Tras desenlazarlas, nos despedimos, deseándonos una feliz noche, y cada cual (yo con mi bulldog y él con su Collie) se fue por su lado. Subiendo minutos después hacia casa en el ascensor reflexioné sobre mi interlocutor y sus palabras. Se me había presentado como argentino, pero, según confesión propia, residía en España y antes lo había hecho en Sudáfrica. ¿Por qué su argentinidad era menos cuestionable que la dudosa, a su juicio, de Cortázar? ¿Por qué a Cortázar se le mide la argentinidad con un termómetro de mercurio tan espeso? No deja de ser curioso que yo me sienta atrapado por un imaginario como es el argentino, creado por un escritor que yo considero argentino, pero que algunos argentinos lo encasillan (casi) en la categoría de escritor no argentino.

Sin entrar en los razonamientos de ese absurdo, me pregunto, en este sentido, ¿cómo es posible, por tanto, que en mi adolescencia, en una clase de instituto de secundaria de mi ciudad, leyera por primera vez en la asignatura de Lengua de la editorial Anaya el fragmento de un cuento que transcurría en Banfield y que trataba de una pluma de pavo real y de Hugo y de Lila y de una familia que quería deshacerse de una invasión de hormigas en su jardín, y a partir de ese momento reconociera a esos quince mil kilómetros de distancia qué era lo argentino, y que, con los años, tras mis propios viajes a la Argentina, viera y supiese que esas calles, las personas, todo obedecía a la perfección a la idea que yo me había fijado a través de los relatos, de las novelas que Julio Cortázar había escrito?

Nadie ignora que la literatura instaura imaginarios y hace que se vuelvan creíbles en el ámbito social y en la conciencia de la persona, por eso puedo decir que yo conocía Buenos Aires mucho antes de ir realmente a Buenos Aires, conocía cómo hablaban los porteños, de qué modo se vestían, conocía lo hermoso que es caminar sin rumbo por Diagonal Norte una tarde otoñal y de repente detenerse y tomar un café en un solitario bar de barrio y ver pasar la gente por delante de la cristalera. Eso lo supe por Cortázar. También supe por él que el metro de París es un mundo simétrico al exterior pero independiente de este, habitado por personas sujetas a ritmos de vida distintos, aunque con las mismas angustias vitales que las de los individuos externos, tipos que se hunden en sueños como Lucho que sube en la parada de la rue du Bac y entonces ahí anda Dina y las manos de ambos se rozan y producen el encuentro, 
supe que París es un dédalo de calles, desde este Pont des Arts hasta la rue Férou o la place de la Contrescarpe, la Ille Saint-Louis, los bulevares del norte y sus pasajes, sus galerías (la Vivienne, tan cortazariana), la vívida place du Général Beuret donde él escribió Rayuela y fue razonablemente dichoso. Julio Cortázar amó Buenos Aires y amó París, son los referentes nucleares (la geografía) a través de los que emerge su sólida obra, ¿para qué insistir con el tema de su nacionalidad? Anoto esta última frase interrogativa en la Moleskine y salgo a flanear.

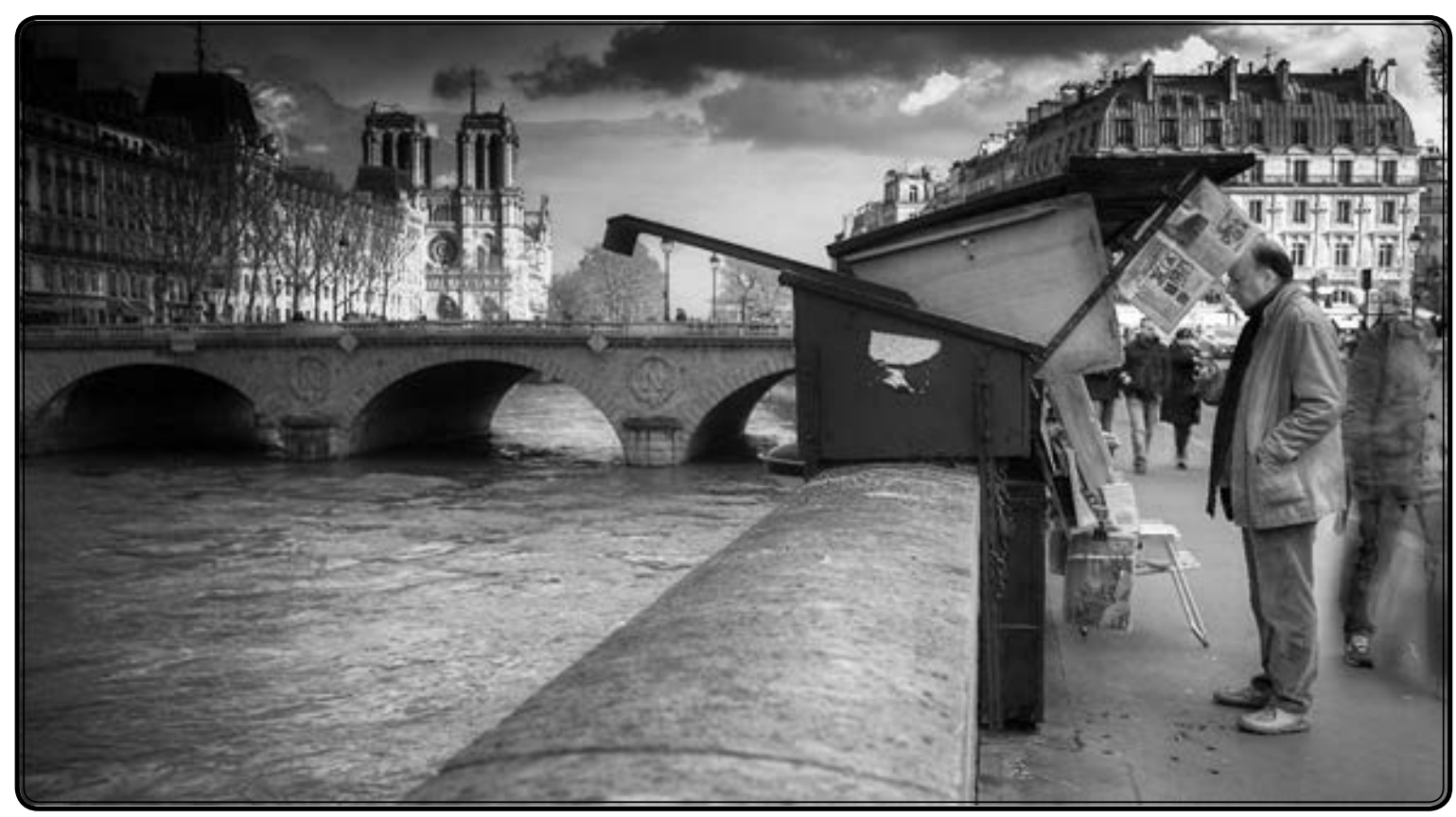

Miguel Herráez en uno de los populares puestos de libros a orillas del Sena, junto al Pont Saint-Michel, distinguiéndose al fondo Notre-Dame. En el pretil de piedra, que se observa a la izquierda de la fotografía, es exactamente el punto en el que Johnny Carter y Bruno, su biógrafo, se reúnen una noche en el cuento "El perseguidor", de Julio Cortázar". La fotografía, cuya autoría es de Carlos Martínez, enfoca en diagonal desde la rue Gît-le-Coeur, donde se halla el famoso Beat Hotel, en el que a finales de los años cincuenta se hospedaron Allen Ginsberg, William Burroughs y Gregory Corso, entre otros. 